\title{
LXXIX. Ionization by collision in helium
}

\section{E.W.B. Gill M.A. B.Sc. \& F.B. Pidduck M.A.}

To cite this article: E.W.B. Gill M.A. B.Sc. \& F.B. Pidduck M.A. (1912) LXXIX. Ionization by collision in helium, Philosophical Magazine Series 6, 23:137, 837-849, DOI: 10.1080/14786440508637279

To link to this article: http://dx.doi.org/10.1080/14786440508637279

曲 Published online: 08 Jun 2010.

Submit your article to this journal

Џ Article views: 4

Q View related articles $\sqsubset$

7 Citing articles: 10 View citing articles 
substance like carbon under bombardment by a rays furnishes a new means of investigating the process by which gases are occluded in carbon, and probably also in other substances.

In conclusion, I wish to express my gratitude to Profesor McLennan for his suggestions and help throughout the course of this investigation.

Physical Laboratory,

Ứniversity of Toronto.

LXXIX. Ionization by Collision in Helium. By E. W. B. Gill, M.A., B.Se., Fellow of Merton College, Oxford, and F. B. PrDduck, M.A., Fellow of Queen's College, Oxford *.

7 THE theory of the ionization of gases by collision, due to Professor J. S. Townsend, has been experimentally verified for a large number of gases $\dagger$, among them being helium $\neq$. In the first experiments made by the authors with helium, the gas was not quite pure (probably about 2 per cent. of impurity being present) and there was good reason for supposing that these slight traces of impurity exercised a very considerable effect upon the ionizing powers of the ions. A few experiments were performed at the time, after the gas had been purified by pumping into a chamber containing charcoal and immersed in liquid air. The supply of liquid air was then limited and only a few results were obtained, but they were sufficient to show that the impurities exercised an effect which was very large in comparison with the amount present.

The ionizing powers of both negative and positive ions, especially the latter, were increased, and as a necessary result the minimum sparking potential was lowered. It was actually reduced from 232 volts to 203 , and it was conjectured that for absolutely pure gas it would be not lower than 190 volts.

A continuous supply of liquid air having since become available, the experiments were repeated and have shown that with careful purification the ionizing powers of the ions are increased even more than was thought possible; for example, the minimum sparking potential was found to be about 160 volts instead of the 190 volts conjectured.

Before giving other results and the experimental methods

* Communicated by Prof. J. S. Townsend.

$\dagger$ J. S. Townsend, 'Theory of Ionization of Gases by Collision.'

I Phil. Mag. [6] vol, xvi. 1908, p. 280. 
used, it will be useful to indicate the usual way of estimating the efficacy of the ions in producing new ions by collision with the uncharged molecules of a gas.

If $n_{0}$ ions are set free at the surface of one of two parallel plates, and an electric force of $X$ volts per cm.' is applied, the number of ions reaching the other plate exceeds $n_{0}$ owing to the formation of fresh ions by collisions in the space between the plates. If on the arerage each negative ion creates $\alpha$ new ions of each sort per centimetre, and each positive ion $\beta$, the number $n$ reaching the other plate is given by

$$
n=n_{0} \frac{(\alpha-\beta) e^{(\alpha-\beta) d}}{\alpha-\beta e^{(\alpha-\beta) d}},
$$

where $d$ is the distance between the plates.

It is perhaps unnecessary to state that the distance $d$ between the plates must be long compared with the mean free path of the ions.

This formula gives at once a method for estimating $\alpha$ and $\beta$ experimentally; for if the plates are put at three different distances $d_{1}, d_{2}, d_{3}$ with corresponding potential-differences $\mathrm{X} d_{1}, \mathrm{X} d_{2}, \mathrm{X} d_{3}$, and $n_{1}, n_{2}, n_{3}$ are the numbers of ions arriving at the positive plate $\left[n_{0}\right.$ being in each case the same], then $\alpha$ and $\beta$ may be determined from the observed ratios $n_{2} / n_{1}$ and $n_{3} / n_{2}$.

If more distances be taken, the fact that any three readings give the same values of $\alpha$ and $\beta$ affords a test of the truth of the theory.

The values $\alpha$ and $\beta$ having been found, there are, however, other methods of testing the theory.

Evidently $\alpha$ and $\beta$ depend both npon the electric force $\mathrm{X}$ and upon the pressure $p$; and it may be proved that $\alpha / p$ and $\beta / p$ must be functions of $\mathrm{X} / p$. It is usual to draw curves with $\mathrm{X} / p$ as abscissa, and $\alpha / p, \beta / p$ as ordinates, and it is found that the points in one figure all lie on one curve, showing that the functional relation is satisfied.

The most effective test, however, is obtained by calculating the distance between the plates for which sparking is to be expected for the given electric force, for if the plates are at a distance $a$ apart given by $\alpha-\beta e^{(a-\beta) a}=0$, the formula shows that the number of ions reaching the electrodes is infinitely great compared with the number originally generated, so that a spark will pass. It may be further shown that this sparking potential $a \mathrm{X}$ is a function of $p a$ only, and it is usual to plot $\mathrm{X} a$ against $p a$. 
The Electrical Measurements.

The experimental arrangements are shown in the figure. The parallel plate electrodes were contained in a glass belljar, and negative ions were set free initially by the incidence of ultra-violet light on the top plate. The metal base had a hole bored in it covered by a quartz plate, through which the light entered. The upper plate, of zinc, was fixed to a micrometer-screw which could be turned from the outside, and by means of which the plates could be put accurately at any desired distance apart, from 1 to $11 \mathrm{~mm}$. The lower plate, also of zinc, had holes cut in it through which the light might pass, and was attached to the top part of the apparatus by four ebonite pillars. To improve the insulation these pillars were encircled about halfway up by tinfoil connected to earth. The upper plate was insulated from the turning-handle by ebonite and connected to the electrometer ; the lower plate was connected to the base, which in turn could be put to any desired potential by connecting to a battery of small storage-cells.

The wires leading to the upper plate and to the tinfoil over the ebonite pillars were taken out of the jar through two ebonite plugs fixed to the glass.

The joints were made air-tight with a plastic cement, while the turning-handle passed out through a tightly fitting brass collar made to fit the top of the bell-jar and rendered air-tight by being covered on top with vaseline.

The ultra-violet light was produced by a sprark-gap in a leyden-jar circuit, and the method of experiment was to turn on the coil for 20 seconds and measure the resulting current through the gas by means of the electrometer and an electrostatic induction-balance *

\section{The Purification of the Gas.}

As the effects of purifying the gas are considerable, it will be well to explain the methods adopted for getting the gas as pure as possible, and to discuss the impurities necessarily present owing to the form of the apparatus.

The helium, which was very kindly given to us by Sir William Ramsay, was kept in the left of the two chambers shown in the diagram [B], being always pumped there at the conclusion of an experiment. The right-hand chamber was reserved for the purification and contained coconut charcoal from which moisture and other occluded

* J. S. Townsend, Phil, Maq. [6] rol. vi. 1908, p. 598. 
gases had been previously driven by heating to about $250^{\circ}$ in a vacuum and pumping off the gases set free.

The mercury pump, shown in conjunction with the threeway tap $D$, could transfer the gas from the apparatus or

Fig. 1.

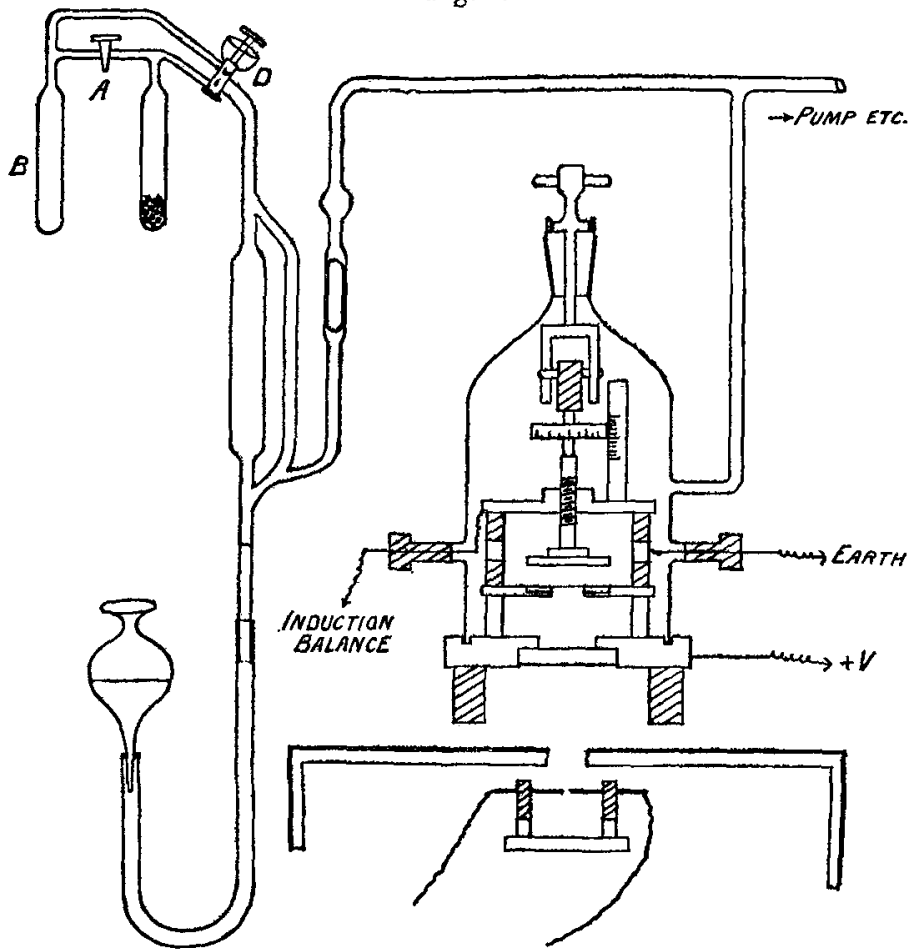

the storage-chamber to the charcoal chamber. $\mathrm{A} \operatorname{tap} \mathrm{A}$ was also inserted for convenience. In all cases the charcoal chamber was first of all surrounded by liquid air and left for some time in order that the charcoal might reabsorb any gases which might have been evolved from it since the previous purification. The tap $D$ was then opened connecting to the apparatus, so that any impurities present there might be absorbed. Finally the helium was admitted to the cold chamber a little at a time, so that the pressure was low, and after being there for an interval was allowed to enter the apparatus by again opening $\mathrm{D}$. It was then pumped back again to $\mathrm{B}$ and the process repeated. The effect of each washing out of the apparatus with pure helium was to reduce very much the amount of any impurity which had not been already taken out. 
The belium upon which the experiments were eventually made was kept in the purification chamber for a considerable time. There is no doubt that the helium was rendered very pure by this process, a fact which was confirmed by spectroscopic observation.

The impurities due to the form of the apparatus will now be discussed :-In the first place a reference to the figure will show that mercury vapour from the pumps and gauge must be present in the bell-jar; but the amount, owing to the low vapour-pressure of mercury, is certainly small, and an experiment was made in which the gas entered the bell-jar through an additional charcoal tube in liquid air of the U-form inserted between the bell-jar and the parts of the apparatus containing mercury. Tne vapour was thus unable to reach the bell-jar, but no variation in the results obtained previously without this precaution could be detected. The effect of the mercury vapour seems therefore inappreciable.

Secondly, the apparatus was not quite (though very nearly) air-tight. The leak, which was tested over about a month, was uniform and caused a rise in pressure of ${ }^{1} 0^{-} \mathrm{mm}$. of mercury a day. An experiment to find $\alpha$ and $\beta$ took usually a little less than an hour, and therefore the pressure of the impurity present at the end of such a set was about $2000 \mathrm{~mm}$. ; the lowest pressure of belium in an experiment was $1.5 \mathrm{~mm}$., and therefore the maximum impurity present was not more than 03 per cent.

In addition there were present vapours given off by the cement and vaseline used in the bell-jar. From the account given of the electrical arrangements it appears impossible to eliminate these; for instance, a quartz window had to be affixed and the various connecting wires had to be taken out of the jar. It is probable that these impurities are very small ; the apparatus was exbausted for about six weeks before the helium was admitted, so that the more volatile gases would probably all have been given off; and certainly any residue was not enough to show on the McIseod gauge, which was read to $\frac{1}{4} \frac{1}{0} \mathrm{~mm}$.

Finally it was necessary to eliminate impurities given off from the plates and the glass by the electric discharge; the small currents in the gas of the order which affect an electrometer do not cause any trouble, but sparking at once brings off gases from the electrodes and the glass, and after a spark had been passed no observation was ever taken till the helium had again been purified. The electrodes were prepared by sparking between them for a very long time at a low pressure before the helium was admitted to the apparatus at all. 
Numerical results obtained.

The results of the experiments for the determination of $\alpha$ and $\beta$ are exbibited in the following tables. The distances $d$ are given in cms., the electric force $X$ in volts per cm., the currents (in arbitrary units) measured as the mean of several observations are given as $q$, while the calculated values of the current $n$ are given in the last row, the values of $\alpha$ and $\beta$, from which they are derived, being shown also in each table. The agreement between the observed and calculated values $q$ and $n$ will be noticed.

TAble I.-Pressure $5.2 \mathrm{~mm}$.

\begin{tabular}{|c|c|c|c|c|c|}
\hline$d \ldots \ldots .$. & 2 & $\cdot 4$ & 6 & 7 & 8 \\
\hline $\mathbf{X}=198 \quad q \ldots$ & $2 \cdot 96$ & $9 \cdot 65$ & $36 \cdot 9$ & $9 \tilde{\mathbf{J}}$ & 1620 \\
\hline $\left.\begin{array}{l}\alpha=5.44 \\
\beta=.07\end{array}\right\} n \ldots$ & $2 \cdot 99$ & $0 \cdot 45$ & 36.5 & 95 & 1710 \\
\hline
\end{tabular}

Table II.-Pressure 5 mm.

\begin{tabular}{|c|c|c|c|c|}
\hline d & $\cdot 2$ & 4 & 6 & 7 \\
\hline \multirow{2}{*}{$\left.\begin{array}{l}X=200 \quad q \ldots \ldots \\
\alpha=5 \cdot 40 \\
\beta=082\end{array}\right\} n \ldots \ldots$} & $2 \cdot 98$ & $9 \cdot 10$ & $35 \cdot 6$ & 111 \\
\hline & $2 \cdot 98$ & $9 \cdot 40$ & 38 & 108 \\
\hline
\end{tabular}

TABLE III.-Pressure $3 \mathrm{~mm}$.

\begin{tabular}{|c|c|c|c|}
\hline$d \quad \ldots \ldots . .$. & 4 & $\cdot 5$ & 6 \\
\hline $\mathrm{X}=240 \quad q \ldots \ldots \ldots$ & 10.5 & 206 & $55 \cdot 1$ \\
\hline $\left.\begin{array}{l}\alpha=5.5 \\
\beta=12\end{array}\right\} n \ldots \ldots \ldots$ & $10 \cdot 4$ & $21 \cdot 4$ & 553 \\
\hline
\end{tabular}


Ionization by Collision in Helium.

TABLE IV.-Pressure $2 \mathrm{~mm}$.

\begin{tabular}{|c|c|c|c|c|}
\hline$d \quad \ldots \ldots \ldots$ & $\cdot 2$ & $\cdot 4$ & 6 & $\cdot 7$ \\
\hline \multirow{2}{*}{$\left.\begin{array}{l}X=240 \quad q \ldots \ldots \ldots \\
\alpha=4 \cdot 2 \\
\beta=\cdot 14\end{array}\right\} n \ldots \ldots .}$. & $2 \cdot 40$ & $5 \cdot 89$ & $17 \cdot 1$ & $38 \cdot 7$ \\
\hline & $2 \cdot 37$ & $5 \cdot 88$ & 18.0 & $39 \cdot 0$ \\
\hline
\end{tabular}

TaBLe V.-Pressure $1 \mathrm{~mm}$.

\begin{tabular}{|c|c|c|c|c|c|c|c|}
\hline$d$ & .......... & $\cdot 4$ & 6 & $\cdot 7$ & $\cdot 8$ & $\cdot 9$ & 1.0 \\
\hline$X=200$ & $q \ldots \ldots$ & $3 \cdot 1$. & $4 \cdot 9$ & $6 \cdot 4$ & $9 \cdot 0$ & ד' 12 & $20 \cdot 4$ \\
\hline $\begin{array}{l}\alpha=237 \\
\beta=\cdot 165\end{array}$ & $n \ldots \ldots$ & 26 & $4 \cdot 6$ & $6 \cdot 4$ & $9 \cdot 0$ & 132 & $22 \cdot 5$ \\
\hline
\end{tabular}

The preceding tables give results from which both $\alpha$ and $\beta$ can be calculated with accuracy ; but for the low values of $\frac{\mathrm{X}}{p} \beta$ becomes very small, and in the following table only $\alpha$ has been found. The value of $\alpha$ can be found from the fact

TABLE VI.

\begin{tabular}{|c|c|c|c|c|}
\hline$d \ldots \ldots \ldots \ldots$ & $\cdot 4$ & $\cdot 6$ & $\cdot 8$ & $d$ \\
\hline $\begin{array}{c}\text { Pressure } 8 \mathrm{~mm} . \\
\qquad \mathbf{X}=80 \ldots \ldots .\end{array}$ & $2 \cdot 4$ & $3 \cdot 6$ & $6: 1$ & $2 \cdot 20$ \\
\hline$X=160 \ldots \ldots$ & 677 & $17 \cdot 5$ & 49 & 4.77 \\
\hline $\begin{array}{r}\text { Pressure } 10 \mathrm{~mm} . \\
X=200\end{array}$ & $9 \cdot 4$ & 35.7 & $\ldots$ & อั60 \\
\hline $\begin{array}{l}\text { Pressure } 25 \mathrm{~mm} . \\
\quad \mathrm{X}=125 \ldots \ldots\end{array}$ & $6 \cdot 7$ & $12 \cdot 7$ & $\cdots$ & $3: 18$ \\
\hline$X=250 \ldots \ldots$ & 72 & 295 & $\cdots$ & $7 \cdot 13$ \\
\hline
\end{tabular}

that for small values of $\beta$ the general equation for the current reduces to $n=n_{0} e^{a d}$. The currents for two distances are 
844 Messrs. E. W. B. Gill and F. B. Pidduck on

sufficient to find $\alpha$, and in general only these two readings were taken. If more are taken there is verification, but it has not been thought necessary to show this agreement for these cases as in tables I. to V.

The values of $\alpha$ are given in the last column, the currents from which they are obtained being in the same row.

Fig. 2.

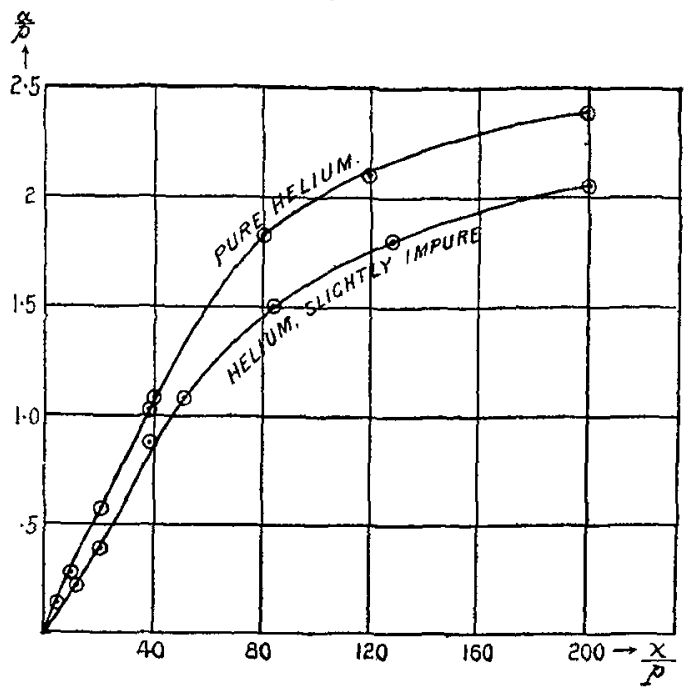

Fig. 3.

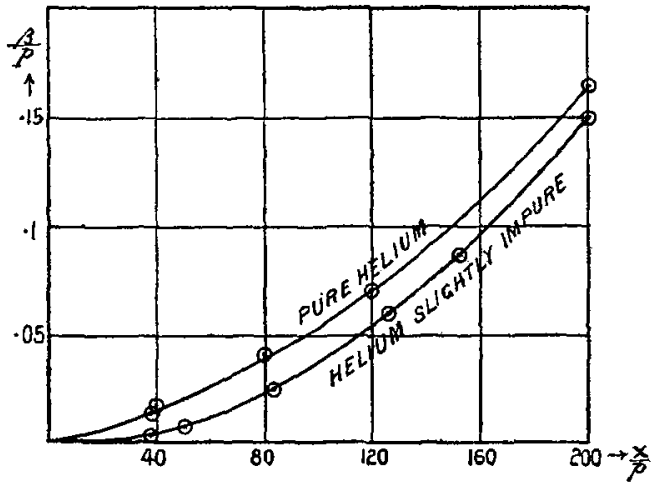

The values of $\frac{\alpha}{\ddot{p}}$ and $\frac{\beta}{p}$ are plotted against $\frac{\mathrm{X}}{p}$ in figs. 2 and 3 , and it will be seen that the points lie on a continuous curve, proving that the functional relations between $\frac{\alpha}{p}, \frac{\beta}{p}$, and $\frac{\mathrm{X}}{\mathrm{p}}$ are satisfied. 
Iunization by Collision in Helium.

The values obtained are exhibited in the following table :-

TABLE VII.

\begin{tabular}{|c|c|c|}
\hline$\frac{\mathrm{x}}{p}$ & $\frac{\kappa}{p}$ & $\frac{\beta}{p}$ \\
\hline 5 & $\cdot 126$ & \\
10 & $\cdot 27$ & \\
20 & $\cdot 57$ & \\
38 & $1 \cdot 03$ & $\cdot 0135$ \\
40 & $1 \cdot 08$ & .0164 \\
80 & $1 \cdot 83$ & .040 \\
120 & $2 \cdot 1$ & .070 \\
200 & $2 \cdot 37$ & $\cdot 165$ \\
\hline
\end{tabular}

The curves obtained in 1908 for helium with an estimated impurity of about 2 per cent. are also put in the figs. 2 and 3 , showing that both $\alpha$ and $\beta$ are diminished by a trace of impurity.

\section{The Sparking Potentials.}

The values of $\alpha$ and $\beta$ given above determine the sparking distance $a$ for the various pressures and electric forces from the formula $\alpha-\beta e^{(\alpha-\beta) a}=0$. This was verified by gradually increasing the distance between the plates, keeping the electric force X per cm. constant; the distances $a^{\prime}$ at which the spark first appeared together with the corresponding sparking potential $a^{\prime} \mathrm{X}$ are given below, the agreement between $a$ and $a^{\prime}$ is very good.

Table VIII.

\begin{tabular}{|c|l|l|l|l|}
\hline $\mathrm{X}$. & $p$. & $a$. & $a^{\prime}$. & $\mathrm{V}$. \\
\hline 240 & 2 & $\cdot 84$ & $\cdot 81$ & 194 \\
240 & 3 & $\cdot 71$ & $\cdot 71$ & 170 \\
200 & 5 & .79 & $\cdot 78$ & $15 \beta$ \\
198 & $5 \cdot 2$ & .82 & $\cdot 83$ & 164 \\
\hline
\end{tabular}


846 Messl's. E. W. B. Gill and F. B. Pidduck on

These sparking potentials $\mathrm{V}$ are plotted as usual in fig. 4 against $p a^{\prime}$, and to get more points on the curve the following sparking potentials were also observed in the above described way, but without obtaining the values of $\alpha$ and $\beta$.

TABLE IX.

\begin{tabular}{|c|l|}
\hline$p a^{\prime}$. & V. \\
\hline 1.87 & 175 \\
498 & 162 \\
16 & 210 \\
$22 \cdot 4$ & 240 \\
35.2 & 280 \\
\hline
\end{tabular}

Fig. 4.

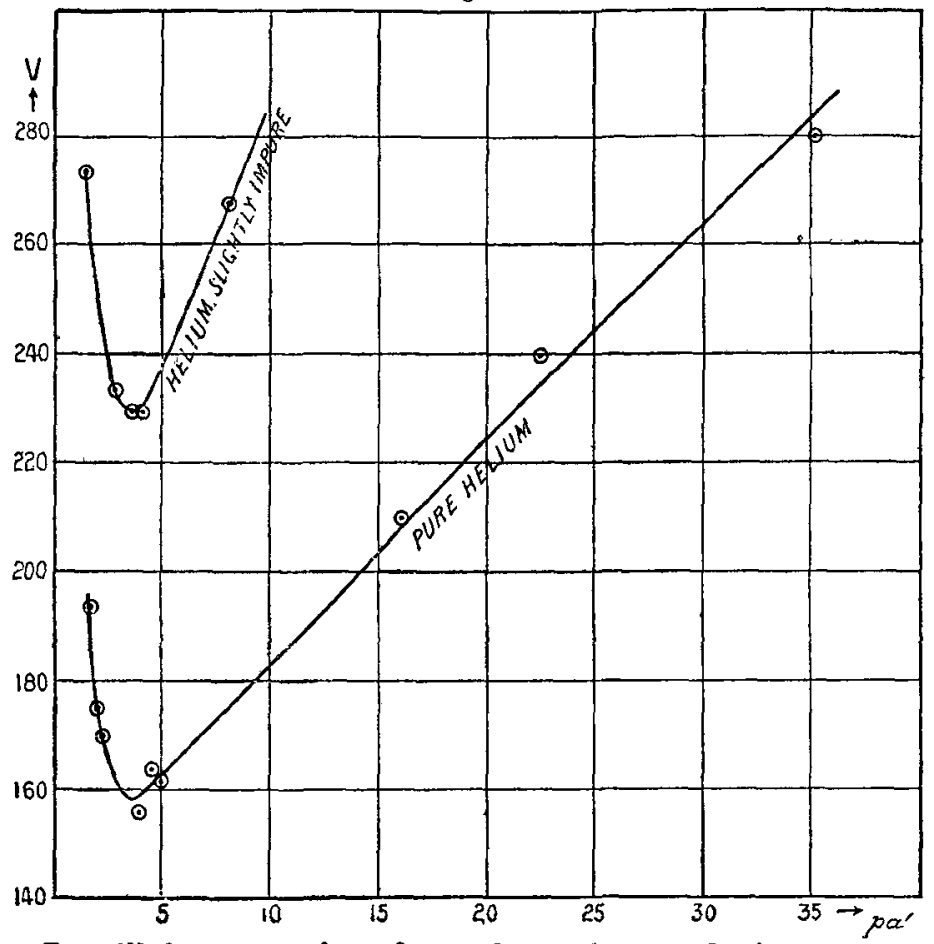

It will be seen that for values of $p$ and $a^{\prime}$ such that $v a^{\prime}=4$, a discharge will pass if 156 volts are applied; and it 
is necessary in consequence to take some precautions in obtaining the sparking potentials. At the higher pressures the distance from the charged plate to the earth connexion to the ebonite supports may be such that $p a^{\prime}$ is about 4 , and a discharge will pass to the supports before the proper potential is reached for a discharge between the plates. To guard against this in all the above determinations ('Tables VIII. and IX.) the supports were put at a potential of 75 volts.

At the lower pressures the spark would often pass round the back of the upper plate in a curved path, in the same way as in a Hittorf tube, the $p a^{\prime}$ for the curved path giving a lower value of $\mathrm{V}$ than the $p a^{\prime}$ for the straight path between the plates. This difficulty only occurs for values of $p a^{\prime}$ considerably less than 4 , and rendered it impossible to find the sparking potential for $p=1, \mathrm{X}=200, \alpha=2 \cdot 37, \beta=\cdot 165$, for which the calculated $p a^{\prime}$ is $1 \cdot 2$.

The comparison of the results so far obtained with those obtained previously with a slightly impure gas are so striking that a set of experiments were made to find the effect upon $\alpha$ and $\beta$ of adding known amounts of impurity. The leak of the bell-jar per day afforded a convenient method of adding known amounts of air to the helium, and the following results were obtained for the currents between the plates for different distances, the current for distance $d=\cdot 2$ being always taken as 10 .

TABLE X.

Helium pressure $5 \mathrm{~mm}$. $\mathrm{X}=200$.

\begin{tabular}{|c|c|c|c|c|c|c|}
\hline$d \ldots \ldots$ & 2 & $\cdot 4$ & 6 & 7 & 8 & $\cdot 9$ \\
\hline Pure Helitım & 10 & $31 \cdot 3$ & 119 & 372 & & \\
\hline Helium with 1 in 400 air.. & 10 & $28 \cdot 6$ & 97 & 228 & 790 & \\
\hline$" 2$ in $400 \ldots .$. & 10 & $29 \cdot 1$ & $90 \cdot 5$ & 194 & 612 & \\
\hline$" 3$ in $400 . .$. & 10 & $29 \cdot 4$ & $92 \cdot 7$ & 172 & 408 & 2410 \\
\hline
\end{tabular}

The values of $\alpha$ and $\beta$ were calculated from these figures and are given below, it not being thought necessary to include for comparison the currents calculated from the values, although the calculation was actually performed and the agreement found as good as those given in tables $\mathrm{I}$. to $\mathrm{V}$.

The sparking distances $a^{\prime}$ and the corresponding sparking: potentials $\mathrm{V}$ are also given. 
TABLE XI.

Helium. $p=5 \mathrm{~mm}$. $\mathrm{X}=200$.

\begin{tabular}{|c|c|c|c|c|}
\hline & $\kappa$. & $\beta$. & $a^{\prime}$. & V. \\
\hline Pure Helium............... & $5 \cdot 4$ & .082 & .78 & 156 \\
Helium +.25 p.c. air ..... & $5 \cdot 1$ & .069 & .85 & 170 \\
Helium +.5 p.c. air........ & $5 \cdot 0$ & .065 & .88 & 176 \\
Helium +.75 p.c. air ...... & $5 \cdot 0$ & .051 & .93 & 187 \\
\hline
\end{tabular}

General Discussion of Results.

The last table show'svery clearly the effect of impurities upon the ionizing powers of the ions. As far as $\alpha$ is concerned the effect of 3 parts in 400 of air is to reduce the value of $\alpha$ by about 8 per cent., but the effect upon $\beta$ is very much greater, reducing it from $\cdot 082$ to $\cdot 051$, that is by nearly 40 per cent. The other two values of $\beta$ are not necessarily very accurate, as they were not tested by passing a spark for fear of adding more impurities to the gas, but the value $\cdot 051$ was thus tested and found correct, as was the value $\cdot 082$ in the course of the experiments given in Table II.

A possible explanation for the fact that the impurities have a much greater effect upon the positive than upon the negative ions, is that they more readily attach themselves to the slow moving positives than to the much faster negatives; the positives thus loaded are less effective in producing fresh ions by collision, because they are longer in reaching the critical velocity necessary for ionization. Experiments upon the velocities of the positive ions in helinm should give interesting results. The reduction of $\beta$ makes a very great difference to the sparking potential, less than 1 per cent. of impurity bringing it from 156 to 187 volts.

The minimum sparking potential attained of 156 volts is far below that observed before for any other gas ; those of nitrogen 298 volts, argon 233 volts, and hydrogen 273 volts, being the three lowest previously obtained.

A formula can be obtained for $\frac{\alpha}{p}$ in terms of $\frac{\mathrm{X}}{p}$ by making simple assumptions as to the effects of collisions on the velocity of the ions *.

* J. S. Townsend, 'Theory of Ionization of Gases by Collision, p. 23 . 
Thus, if $\frac{1}{\mathrm{~N}}$ is the mean free path for $1 \mathrm{~mm}$. pressure, $\mathrm{V}$ the least potential difference between the ends of. a path to cause a negative ion to acquire sufficient velocity to generate others by collision, then when $p=1$

$$
\alpha=\mathrm{N} e^{-\frac{\mathrm{NY}}{\overline{\mathbf{x}}}}
$$

'I'he agreement of the $\alpha$ 's found with this formula for the values $\mathrm{N}=2 \cdot \mathrm{y}, \mathrm{V}=12 \cdot 3$, is given below.

TABLE XII.

\begin{tabular}{|c|c|c|c|c|c|c|}
\hline $\mathrm{x}$ & 200 & 160 & 120 & 80 & 40 & 20 \\
\hline$\alpha$ found experimentally & $2 \cdot 37$ & $2 \cdot 27$ & $2 \cdot 1$ & 1.83 & $1 \cdot 07$ & 57 \\
\hline $\mathrm{N} e^{-\frac{}{\mathrm{X}}}$ & $2 \cdot 35$ & $2 \cdot 26$ & $2 \cdot 1$ & $1 \cdot 82$ & $1 \cdot 18$ & .50 \\
\hline
\end{tabular}

This value of $\mathrm{V}$ is also lower than for any other gas, the next, among those examined, being hydrochloric acid for which $\mathrm{V}=16.5$ volts. For air it is 25 volts.

In conclusion, we wish to express our thanks to Prot. Townsend for valuable advice during the course of the experiment.

LXXX. Remarks on the Production of Condensation. Nuclei in Air and in Vupow's by Intense Cooling and by Liltra- Tiolet Light.

To the Editor's of the Philosophical Magazine.

\section{Gentlemen,-}

T $N$ connexion with the paper by Mr. Gwilym Owen which 1 appeared in the Philosophical Magazine for Octoler, 1911, p. 563, entitled "Note on the Production of Nuclei in Air by Intense Cooling," I shonld like to lay betore you sume considerations which seem to explain the results there obtained. These considerations are based on a series of experimental researches on allied suljects which I carried out together with Prolessor P. Lenard *.

* P. Lenard and C. Ramsauer: "Ueber die Wirkungen sehr kurzwelligen ultravioletten Lichtes auf Gase und über eine selhr reiche Quelle dieses Lichtes," Heidelberyer Akudemie. Five Parts: I. Aug. D, 1910 ; II. Nov. 5, 1910; III. Dec. 20, 1910; IV. June 9, 1911; V. Aug. 4, 1911 .

Phil. Mag. S. 6. Vol. 23. No. 137. May 1912. $3 \mathrm{~K}$ 